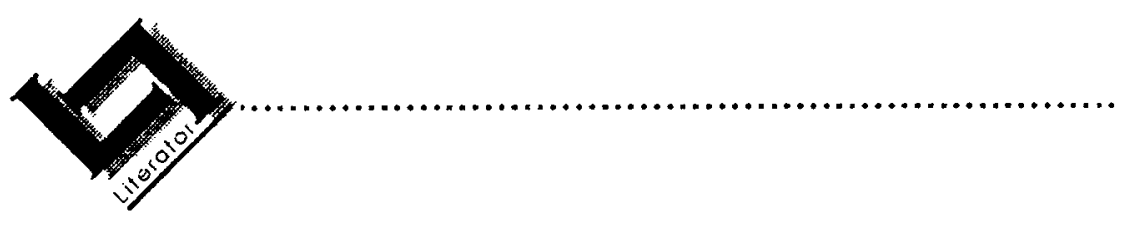

\title{
Teksheid: Die kreatiwiteitsgraad van 'n teks as aanduiding van die grense tussen taaldissiplines
}

\author{
Hans du Plessis \\ ATKV-skryfskool \\ Potchefstroomse Universiteit vir $\mathrm{CHO}$ \\ POTCHEFSTROOM \\ E-pos: asshgwdp@puknet.puk.ac.za \\ Abstract
}

Textness: The degree of creativity of a text as marker of the boundaries between language disciplines

In this article it is proposed that the traditional distinction between linguistics and literature poses more questions than it gives answers. In view of the modern academic context of focus areas and research programmes the focus should rather be on the similarities between the subdisciplines of language than on the differences. The growth of creative writing as science and the development of the discipline of language usage as applied in South Africa force us to look afresh at language-related subjects. Text is postulated as the binding factor between the study of linguistics, literature, creative writing and language usage. But text has to be defined in terms of the degree of creativity, thus indicating text as the binding factor of a given text, and creativity as the differentiating factor.

\section{Inleiding}

Wetenskap in die moderne wêreld stel nuwe eise aan die beoefenaar en die leermeester daarvan. Hierdie insetsin veronderstel dat daar anders gekyk behoort te word na iets soos byvoorbeeld die verband tussen die taalverwante wetenskappe. Verder eis die nuwe akademiese konteks, nie net in Suid-Afrika nie, 'n versamelende blik op eenhede wat in die ouer konteks as los entiteite bestaan het. Die verskil tussen byvoorbeeld taal- en letterkunde binne die tradisionele taaldepartement op skool en universiteit is streng gehandhaaf, sonder om ooit werklik die sin van 'n rigiede grens te bevraagteken. Die huidige konteks van fokusareas, 
navorsingsprogramme en subprogramme dwing die beoefenaar en die leermeester van die wetenskap egter om nuut te kyk na die wetenskap in die algemeen en die eie dissipline in die besonder. Dit het belangriker geword om na die gemeenskaplike te vra. Wat bind die taal- en die letterkunde saam in een navorsingsarea, en by implikasie, in een onderrigprogram?

Die moderne navorsings- en onderrigklimaat van die taalvak word egter ook beïnvloed deur die opkoms van die skryfkuns as wetenskap en die groei van die sogenaamde taalbeheersingsmodel. Veral laasgenoemde, wat die tradisionele taalpraktyk of language usage insluit, maak die postulering van 'n oorkoepelende taaldissipline al dringender. Maes et al. (1994:1) stel die groei van hierdie wetenskap duidelik:

Taalbeheersing is begonnen als praktische en ondersteunende discipline en is gegroeid in een periode waarin beleidmakers steeds nadrukliker aandrongen op een groter maatschappelijk draagvlak voor letterenopleiding.

Dit is tog so dat daar tradisioneel sterker gefokus word op die verskil tussen taal- en letterkunde as op die ooreenkoms. Hierdie ietwat veralgemenende stelling kan goed afgelei word van die feit dat taal- en letterkunde in Suid-Afrika op skool, en veral ná skool aan tersiêre inrigtings, aanvanklik duidelik as subdissiplines van mekaar onderskei is. Ofskoon daar oor die jare in die vakliteratuur enkele navorsingsverslae verskyn oor die verband tussen taal- en letterkunde (Scholtz, 1978; Gräbe, 1979; Snyman, 1981 en Du Plessis, 1983), benadruk dié verslae die verskil tussen taal- en letterkunde eerder as die ooreenkoms.

Met die opkoms van skryfkuns as wetenskap en met die toenemende belangstelling in die taalgebruikskunde, word dit egter belangrik om ook sterk op die ooreenkomste te begin fokus. Die postuleer van 'n sterker bindende faktor tussen die verskillende verwante dissiplines wat met taal te make het, plaas die studie van taal binne die nuwe akademiese konteks as 'n navorsings- en onderrigproram sinvol bymekaar.

Die logiese bindende faktor is natuurlik taal, maar omdat die begrip taal baie wyd strek, en ook dissiplines soos psigologie of filosofie bytrek, word in hierdie artikel in die eerste plek gesoek na 'n bindende faktor ten einde die dissiplines as hegter eenheid te beredeneer. Die probleem is daarin geleë dat met die opkoms van skryfkuns en taalbeheersing dit al moeiliker word om die bindende te beskryf omdat die onderskeidende tradisioneel belangriker was.

Hieruit volg dan die vraag: Wat sou as bindende studie-objek beskryf kan word? Die voor die hand liggende is dat taal in wese kommunikasie- 
middel is, en dat dit waarmee gekommunikeer word, die gemeenskaplike die beste omskryf, en dit dan die bindende moet wees. In hierdie artikel word geargumenteer dat daar algemeen aanvaar word dat teks die gebruiksmiddel is waarmee gekommunikeer word. Daarom lyk dit logies om uit te gaan van die standpunt dat teks vir die verwante taaldissiplines die gemeenskaplike studie-objek is, en dat die verskil tussen die dissiplines op een of ander manier met verwysing na die onderskeidende aard of funksie van die teks gedefinieer kan word.

Hierdie artikel het ten doel om teks as bindende faktor te beredeneer, en terselfdertyd ook in die beskrywing van die onderskeibare aard en funksies van teks die verskille te beskryf.

Teks kan op vele maniere benader en beskryf word, maar ter wille van hierdie artikel word daar hipoteties uitgegaan van die aanname dat 'n veranderlike, soos die graad van kreatiwiteit van 'n teks, die dissipline wat dit bestudeer, kan voorspel. Hipoteties word geredeneer dat die graad van kreatiwiteit onder andere deur ' $n$ veranderlike, soos duidigheid gemerk word, sonder om daarmee voor te gee dat duidigheid die enigste veranderlike kan wees. Verder word die kreatiwiteitsgraad van 'n teks in hierdie artikel gebruik om die teksheid van 'n teks te bepaal. Vir die doel van hierdie argument word tekste gradeerbaar met verwysing na teksheid. Teksheid hou in hierdie artikel verband met die kreatiwiteitsgraad van die besondere teks, en kreatiwiteit word bepaal deur die duidigheidsgraad van die teks. Hiermee word nie voorgegee dat teksheid slegs deur kreatiwiteit, en kreatiwiteit slegs deur duidigheid bepaal word nie. Hierdie twee veranderlikes word egter ter wille van die verduideliking van 'n teoretiese stelling gebruik.

Teks bind die taal-, letterkunde, skryfkuns en die preskriptiewe taalkunde, maar die teksheid van die teks onderskei hierdie dissiplines weer van mekaar.

In die volgende afdeling word oorsigtelik aan die term teks aandag gegee, vir sover teks as gemeenskaplike objek beskou kan word. In die laaste afdeling word teksheid op 'n skaal van kreatiwiteit geplaas, ten einde dié graadverskil te gebruik om die onderskeid tussen dissiplines te probeer tref.

\section{Teksheid}

'n Mens sou vir die doel van hierdie ondersoek kon volstaan met 'n baie algemene omskrywing van wat teks is, soos byvoorbeeld dié van Carstens (1997:5): 
'Teks' is ' $n$ tegniese term wat gebruik word om die verbale weergawe van ' $n$ bepaalde taalgebeurtenis in ' $n$ besondere taalkonteks aan te dui. Meestal word hiermee geskrewe werk bedoel, hoewel gesproke werk in getranskribeerde vorm (as artefakte) ook ingesluit word.

Teks is dan teen hierdie agtergrond bloot die produk van enige kommunikatiewe taalhandeling. Verder is dit in die lig van wat met hierdie artikel bereik wil word, waarskynlik ook moontlik om met 'n algemene omskrywing, soos dié van Johl (1991:530), klaar te kom:

Teks word tans, veral onder die invloed van die Peirceaanse Semiotiek, taamlik algemeen gesien as 'n stuk taalgebruik wat sintakties, semanties en pragmaties ' $n$ samehangende eenheid vorm.

Dit blyk uit hierdie algemene omskrywings immers dat teks ' $n$ stuk taal is waarbinne daar ' $n$ eenheid is. Dit is egter juis die doel van hierdie artikel om teks só te probeer omskryf dat die gemeenskaplike in die omskrywing van teks in die letterkunde, die taalkunde, taalbeheersing en die skryfkuns beskryf word. Die vertrekpunt van die argument is dat die sogenaamde tekstipe wat vir die onderskeie dissiplines tradisioneel onderskei sou kon word, inderwaarheid bloot 'n ander graad van teksheid veronderstel, en nie verskillende tekstipes nie. Dit lei daartoe dat daar tog in hierdie afdeling vlugtig aandag geskenk moet word aan die onderskeidende omskrywing van teks, afhangende van die dissipline waarbinne teks beskryf word.

Thomas F. Broden (1999:91/92) toon in sy resensieartikel van Francois Rastier se Meaning and textuality aan dat Bastier weier om 'n keuse te maak tussen

... theories of text that claim to originate in linguistics but are condemned to failure by a formalist thrust that makes them neglect semantics; and, on the other (hand) semiotic and cognitive theories that have no direct link with linguistics and reduce textual semantics to a combination of concepts or of universal primitives that do not take into account the specificity of the language in which the texts are articulated.

As 'n mens 'n keuse sou maak, is jy natuurlik terug in 'n debat wat tot die doel van hierdie artikel niks bydra nie.

Daarom sou teks as gemeenskaplike faktor vir al die tekswetenskappe aanvaar kan word, maar teks word dan wyd geïnterpreteer sodat dit die gemeenskaplike studie-objek vir al die taaldissiplines word. En ek bly in die argument spesifiek weg van terme soos tekstualiteit of genre omdat teks só beskou word dat dit die linguistiese en literêre definisies daarvan kan insluit. Dit is die preteoretiese term wat hier ter sprake is, sou 'n 
mens kon sê. Dit impliseer dat selfs Lyons (1977) se klassieke onderskeid tussen sisteemsin en tekssin opgehef word. Binne so 'n raamwerk moet selfs die Chomskyaanse sisteemsin van die sogenaamde ideale spreker as teks aanvaar word, of die sin dan deel is van 'n groter geheel of nie. Só gesien, word teks vir die doeleindes van die argument in hierdie artikel, in Lyons (1977:623) se terme, gebruik om te verwys na "any passage, written or spoken, of whatever length, that does form a unified whole". Die lengte van 'n teks is in elk geval volgens Carstens (1999:85) onbepaald, al is daar teksgrense. Hierdie grense het egter met die aard van die teks en die konteks te make. Binne die konteks van die linguistiese analise kan selfs die klankgroep of die sinstuk as teks gehanteer word. Dit sluit aan by Fillmore (1985:11, soos aangehaal deur Carstens, 1997) se siening:

I ... use the word 'text' to designate any whole product of human capacity including thus, words and tone groups at the narrow end of the scope, novels and bodies of law at the wide end.

Teen hierdie agtergrond is dit aanvaarbaar dat die taalkunde, die letterkunde, taalbeheersing en die skryfkuns die studie van teks as objek het. 'n Mens sou in die lig van wat hierbo uiteengesit is, kan argumenteer dat die verskil tussen taal- en letterkunde onder andere lê in die verskil in die aard en konteks van die teks wat binne die tradisionele dissiplines ondersoek word: die taalkunde hou hom teen hierdie agtergrond in SuidAfrika tradisioneel hoofsaaklik besig met die linguistiese struktuur van die niefiksieteks, terwyl die tradisionele letterkunde hoofsaaklik bemoeienis maak met die literêre analise van die fiksieteks. Hierteenoor sou daar verder geredeneer kan word dat die skryfkuns as dissipline die skep van (veral) die fiksieteks as ondersoekgebied het.

Dit blyk uit voorgaande argument duidelik dat sodanige poging tot kompartementering meer vrae as antwoorde laat ontstaan, en verder dat buurdissiplines, byvoorbeeld die kommunikasiekunde of selfs die taalbeheersingsmodel, nie binne hierdie poging tot afbakening plek kry nie.

Dit lyk vir my of teks dan anders benader kan word ten einde dit so te omskryf dat die aard van die teks juis die gemeenskaplike faktor in die studie van taal word en nie een van die onderskeidende merkers nie. Teks is immers die gemeenskaplike beskrywings- of skeppingsobjek van enige wetenskap wat hom met taal wil besig hou. Daar moet daarom in die eerste plek op die gemeenskaplike tussen verwante taalwetenskappe (in die wydste sin van die woord) gekonsentreer word, juis om daarmee 'n gemeenskaplike grond vir hierdie taalverwante wetenskappe te postuleer 
Daarmee word die bestaan van onderskeibare tekstipes egter juis nie ontken nie, maar die beklemtoning van die verskil in die tekstipes wat bestudeer word, kompartementeer die verwante dissiplines te veel, terwyl teks die gemeenskaplike behoort te beskryf.

Daar kan 'n oplossing lê in die aanvaarding van die feit dat tekstipes nie net met verwysing na verskille onderskei word nie, maar dat 'n mens die weg volg wat reeds in die sewentigerjare deur die Amerikaanse linguis John Ross (1973) in sy artikel, "Nouniness", gevolg is. Hiervolgens is daar nie bloot 'n woordsoortkategorie naamwoord nie, maar daar is 'n skaal van naamwoordelikheid. Die beginsel van skalering waarom dit vir Ross gaan, is belangrik vir die doel van hierdie artikel, naamlik dat daar nie net sprake is van 'n woordsoortkategorie wat net [+] of [-]naamwoord is nie. Daar is grade van naamwoordelikheid. Hierdie graadskaal word dan binne Ross se beskouing op 'n sogenaamde klien (squish) aangetoon. Die vertikale as dui die graad van naamwoordelikheid aan, terwyl die veranderlike wat die graad bepaal, op die horisontale as aangedui word. Vergelyk in verband met die toepassing van die skaleringsbeginsel die artikel van Du Plessis (1981) oor die skalering van ou en nuwe inligting.

Dit is dan die sentrale teoretiese stelling van hierdie artikel dat teks as eenheid van taalgebruik nie net in teenoorstaandes, soos [+]fiksie of [-jfiksie, verdeel behoort te word nie, maar dat bepaalde veranderlikes die kreatiwiteitsgraad van 'n teks kan bepaal en dat die kreatiwiteitsindeks van 'n teks die besondere teks se geskiktheid vir die besondere dissipline wat die teks as studie-objek het, bepaal. In hierdie artikel word kreatiwiteit gebruik om die teks se graad van teksheid aan te dui, sonder om daarmee te impliseer dat kreatiwiteit die enigste faktor vir die bepaling van teksheid is

Ten einde die hipotetiese stelling hierbo te toets, moet teks as term eers weer van nader bekyk word, en dan kan 'n teksklien vir die teks se kreatiwiteitsgraad ontwerp word met verwysing na veranderlikes. Uiteindelik moet die wetenskaplike waarde van so ' $n$ klienbenadering bepaal word.

Carstens (1997:92 e.v.) se deeglike bespreking van die aard van die probleem om teks as term te definieer, dui duidelik daarop dat die probleem nie soseer lê in die definisie self nie, maar daarin dat die definisie hoofsaaklik bepaal word deur die definieerder se doel met die teks wat gedefinieer moet word. Die definisie word dus bepaal deur faktore, soos wat ontleed moet word, wat die konteks van die teks is, van watter kant af die teks benader word, en so meer. In hierdie verband is die aanhaling deur Carstens (1997:73) van Durrant en Fabb illustratief 
van die aard van die definisieprobleem: "... the word (text) has various technical meanings for people working in specific disciplines". Daar kan dan saam met Carstens geredeneer word dat die preteoretiese kennis van die begrip definisie onnodig maak. Dit word uit sy poging om 'n linguistiese werksdefinisie van teks te gee, immers duidelik hoe futiel hierdie soort definisie kan wees, want wat meer kry 'n mens bereik as om die 85ste definisie van teks te gee?

In die lig hiervan word 'n teks dan eintlik as sodanig aanvaar op grond daarvan dat ' $n$ stuk taalgebruik binne die kommunikatiewe handeling ' $n$ eenheid vorm. Die eenheid word op drie vlakke bereik, naamlik die strukturele vlak (wat myns insiens dui op 'n fonologiese, morfologiese en/of sintaktiese eenheid). Verder is teks 'n semantiese eenheid en laastens is dit 'n eenheid op die pragmatiese vlak, wat dui op 'n funksionele eenheid.

So ' $n$ beskouing sluit dan nou aan by Johl se omskrywing waarna daar vroeër in hierdie afdeling verwys is, maar sluit ook linguistiese eenhede kleiner as die tekssin in.

Op soek na 'n definisie van die literêre teks stuit die navorser eweneens op die veelheid van definisies wat ook saamhang met die doel van die definiëring van die term teks. Dit word gaandeweg duidelik dat teks in die literêre teorie in elk geval onder een van twee denkrigtings tuisgebring kan word, naamlik as funksie van 'n buitetekstuele konteks of as 'n outonome, selfstandige entiteit (vgl. Johl, 1991:530).

Ook binne die taalbeheersingsbenadering is die teks (en veral dan die preskriptiewe verbetering daarvan) sentraal omdat dit om die sogenaamde funksionele teks gaan (vgl. Jansen, 1998).

Die preteoretiese begrip teks is daarom duidelik genoeg om uiteindelik te stel dat dit in sowel die linguistiese as die literêre teorie aanvaarbaar is om teks te beskou as 'n taaluiting (mondeling sowel as skriftelik) wat 'n strukturele, semantiese en pragmatiese eenheid vorm.

Binne die skryfkuns as dissipline word daar veel minder oor die term teks geteoretiseer, waarskynlik omdat dit binne hierdie wetenskap veel meer gaan om die beginsels en die elemente wat gebruik word om die teks tot stand te bring.

Daar word dus geargumenteer dat teks die gemeenskaplike faktor van die taal-, letterkunde en die skryfkuns is, al word teks op hierdie stadium bloot as preteoretiese term gebruik. 
As ' $n$ mens die preskriptiewe taalkunde, soos veral binne die Nederlandse taalbeheersingsmodel, aanvaar as hiërargies gelyke dissipline (naas taal-, letterkunde en skryfkuns), dan is die studie-objek van die normatiewe beskrywing en voorskrywing ook die teks. Teks word teen die agtergrond hiervan dus die gemeenskaplike (bindende) faktor wat die letterkunde, deskriptiewe en preskriptiewe taalkunde en skryfkuns bind.

Hierdie uitgangspunt fokus dus op die gemeenskaplike tussen dissiplines wat tradisioneel wel as verwant aan mekaar beskou is, maar waarin die verskille eerder as die ooreenkomste beklemtoon is.

Dit is egter wel waar dat al sou die teks as objek vir al die taalverwante dissiplines gepostuleer word, dit logies volg dat die aard en konteks van die teks vir elke dissipline behoort te verskil. Dit is in hierdie opsig dat daar in hierdie artikel verder geargumenteer word dat die verskil 'n skalering van die aard van die teks kan veronderstel. Gestel daar word beweer dat die letterkunde en die skryfkuns hulleself hoofsaaklik besig hou met die fiksieteks en die beskrywende en normatiewe taalkunde hoofsaaklik met die niefiksieteks, dan ontken so 'n tweeledige onderskeid tussen fiksie en niefiksie die bestaan van 'n groot verskeidenheid fiksievlakke tussen die uiterstes van [+]fiksie en [-]fiksie.

So sou 'n fiksieskaal, 'n sintaktiese kompleksiteitskaal, 'n metafoorskaal of ' $n$ kreatiwiteitskaal gebruik kon word om die teks te gradeer. Dit is duidelik dat kwessies soos konteks of ander pragmatiese, semantiese of sintaktiese veranderlikes ook ' $n$ rol kan speel. Dit gaan verder in hierdie artikel daarom dat die graad van 'n teks se kreatiwiteit as objekonderskeiding gebruik kan word. Die onderskeie taaldissiplines hou hulle almal met die studie van die teks besig, maar kan onderskei word van mekaar op grond van iets soos die kreatiwiteitsgraad van die teks en die konteks waarbinne die betrokke teks bekyk word.

\section{Teksheid as skaal van kreatiwiteit}

Teksheid word ter wille van hierdie argument gebruik om te dui op 'n verskeidenheid soorte tekste wat, met verwysing na 'n veranderlike soos kreatiwiteit, kan bestaan, byvoorbeeld 'n meerduidige, komplekse prosaof poësieteks, 'n minder gekompliseerde verstrooiingsteks (byvoorbeeld 'n boekklubroman), 'n gesinstydskrifverhaal, 'n bloot feitelike koerantberig, 'n gebruiksaanwysingsteks, en so meer. Uit hierdie veelheid van tekstipes blyk dit al klaar dat daar nie net sprake is van [+] of [-]kreatiewe teks nie. Tekstipes moet myns insiens op een of ander manier georden kan word, juis as aanvaar word dat teks die gemeenskaplike navorsings-, beskrywings- of voorskrywingsobjek is. Die sentraliteit van die teks as studie-objek in hierdie benadering dwing ' $n$ mens dan om op 
een of ander manier orde en sistematiek te soek in die warboel van tekstipes en hulle kontekste.

Daar sou as vertrekpunt begin kan word by 'n onderskeid wat heel algemeen in die skryfkunsliteratuur getref word, naamlik die verskil tussen 'n triviale teks en 'n literêre teks. Met triviaal word dan meestal 'n niefiksieteks bedoel.

Vir iemand soos Drury (1991:42-51) lê die verskil by implikasie in die duidigheid van 'n teks: 'n eenduidige teks sal as triviale teks deurgaan, terwyl meerduidigheid die literêre teks kenmerk.

Hierdie onderskeid (wat dikwels in die skryfkunsliteratuur op verskillende maniere voorkom) kan waarskynlik die maklikste verduidelik word aan die hand van 'n voorbeeld: gestel jy wil iemand anders winkel toe stuur om iets vir jou te gaan koop, dan is dit die maklikste om vir hom of haar 'n duidelike inkopielysie saam te gee. So 'n notisie moet egter so eenduidig as moontlik wees sodat die gestuurde nie met die verkeerde goed van die winkel af terugkom nie. So sou 'n inkopielys net die basiese inligting bevat, soos: 'n halfbottel Klipdrift, 'n halwe bruin brood en ' $n$ pakkie sout-en-asyn-skyfies. Dié lys is 'n teks met verwysing na 'n taalgebruikshandeling waarmee gekommunikeer word, en waarin daar die nodige eenheid van struktuur, semantiek en pragmatiek is. Hierdie teks is triviaal omdat dit sover moontlik poog om eenduidig te wees.

Dieselfde teks kan egter meerduidig word binne 'n ander konteks, deur byvoorbeeld bloot 'n gedig daarvan te maak:

\section{Boemelaar}

Half Klipdrift

half brood

Simbasout

kraak die bros dood

Die vraag is nie hoe goed die gedig is nie, maar of die gedig meerduidiger is as die notisie. Indien dit so is, is die verskil tussen die triviale inkopielys en die literêre teks onder andere 'n verskil in duidigheid (natuurlik is daar ander faktore wat die verskil merk, en wat op dieselfde manier beskryf kan word). Dit is egter duidelik dat die duidigheidsvlak die kreatiwiteit van die teks beïnvloed. As die duidigheid die een veranderlike is op die horisontale as, dan bepaal dit die kreatiwiteitsgraad van die teks op die vertikale as. Hiervolgens kan dan 'n klien opgestel word wat daarop dui dat die duidigheidsvlak van 'n teks direk verband hou met die kreatiwiteitsgraad van 'n teks. Die verskil tussen die medisynebiljet as teks en die hoogs gekompliseerde literêre teks van, byvoorbeeld Etienne 
Leroux, lê dan in die graad van kreatiwiteit van die teks, wat in hierdie geval gemeet word aan die graad van duidigheid. Hiervoor sou daar dan 'n teksheidsklien as skematiese voorstelling gebruik kan word. Die grondrede vir die keuse van 'n klien is daarin geleë dat daar tussen die eenduidige medisynebiljet en die hoogs gekompliseerde en veelduidige Lerouxteks 'n hele skaal van tekste lè. Die heel kreatiefste teks is, teen die agtergrond van die onderhawige argument, dan "meer teks" (tekser) as die eenduidige (dus mins kreatiewe) teks, byvoorbeeld die strak medisynebiljet of die inkopielys.

\section{Teksheidsklien}

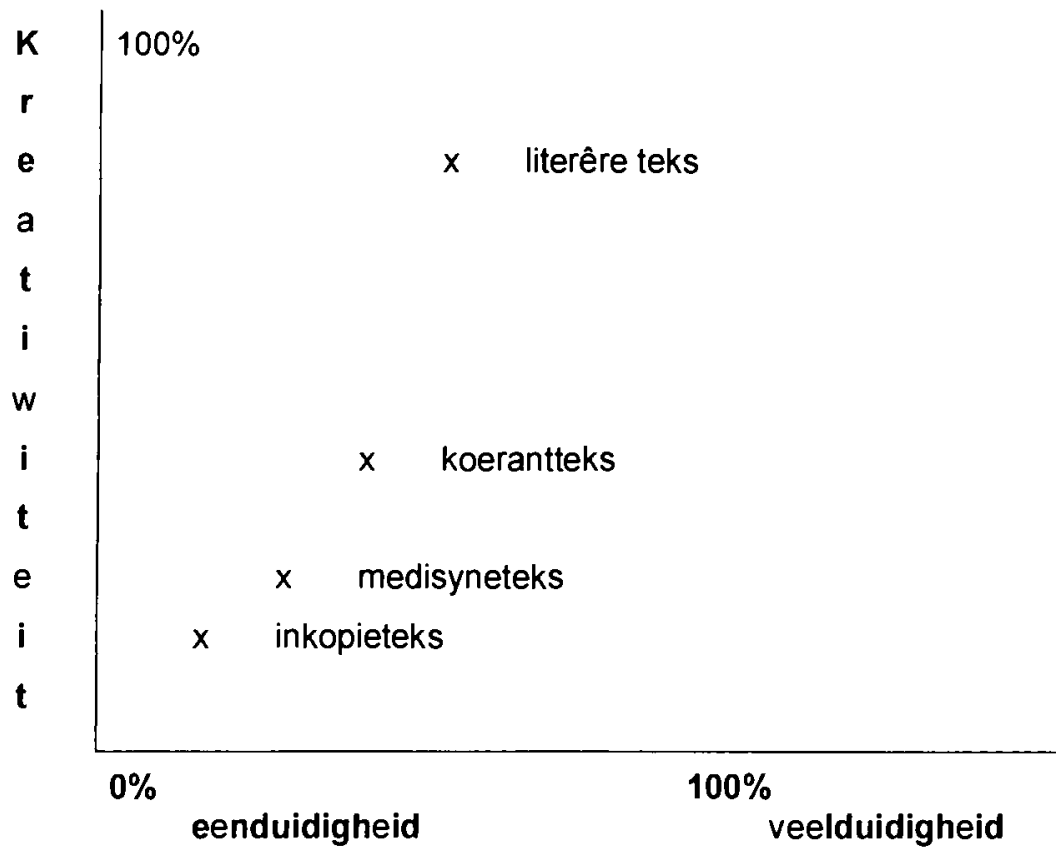

Om te herhaal: natuurlik is duidigheid maar een veranderlike wat die kreatiwiteitskaal van 'n teks bepaal. Ander veranderlikes, byvoorbeeld konteks, metafoorgebruik, sintaktiese kompleksiteit, klankgebruik, of wat ook al, kan ook op dieselfde manier as veranderlikes gebruik word. Die doel van hierdie artikel is egter nie om al die moontlikhede te probeer ontgin nie, maar net om die teoretiese omgewing te vestig, naamlik

- dat taalverwante dissiplines die teks as gemeenskaplike faktor het,

- dat die verskil tussen die dissiplines lê in graad van teksheid wat bestudeer word, en die manier waarop hulle dit bestudeer en 
- dat teks op 'n kreatiwiteitsklien 'n skaal van kreatiwiteit veronderstel wat die verskil tussen die verwante dissiplines kan merk.

Hieruit moet dit dan logies volg dat die skeidslyne tussen die dissiplines nie meer so duidelik loop as wat ons in die verlede so graag wou glo nie. Die studie van die analise van 'n poësieteks is op 'n skaal van "letterkundigheid" dus nie bloot [+]letterkunde nie, want die tekslinguistiek, die skryfkuns, die klankleer, sintaksis of die adviserende insette van taalbeheersing kan almal hierdie teks op verskillende vlakke as teks beskryf, skep of voorskriftelik oor die taal daarin wees.

Die taalverwante dissiplines is daarom nie gekompartementeerde subdissiplines nie, maar verskillende manifestasies van die studie van teks.

\section{Slot}

Die verskil tussen taal- en letterkunde moet nie oorbeklemtoon word nie, maar die ooreenkoms behoort die vertrekpunt te wees. Die opkoms van die skryfkuns as wetenskap en die snelle groei ( $\mathrm{vgl}$. byvoorbeeld $\mathrm{De}$ Wet, 1998) van die taalgebruikskunde veroorsaak dat 'n mens suiwerder moet wees in die formulering van die ooreenkoms en die verskil tussen die aanverwante dissiplines.

Die gebruik van teks as studie-objek in sowel die taal- as die letterkunde, die feit dat die skryfkuns ook die teks as objek het, asook die taalgebruikskunde se gebruik van die term laat 'n mens die ooreenkomste vermoed. Die verskil tussen byvoorbeeld die letterkunde aan die een kant en die taalgebruikskunde aan die ander kant is veral geleë in die aard (graad van) die teks wat bestudeer word en die een belangrike verskil tussen die tekste is ' $n$ verskil in die kreatiwiteitsvlak van die teks: die letterkunde het die hoogs kreatiewe teks as objek, terwyl die taalgebruikskunde hom hoofsaaklik besig hou met die sogenaamde funksionele teks (waaronder die inligtingsteks, die oorredingsteks en die instruksieteks) wat per defınisie minder kreatief en eenduidiger moet wees.

Die skryfkuns werk uiteraard ook hoofsaaklik (hoewel nie uitsluitlik nie) met die kreatiewe teks, maar die skryfkuns het hoofsaaklik die kreatiewe totstandkoming van die teks in die oog. Die skryfkuns wil die kreatiewe teks skep, die letterkunde die bestaande kreatiewe teks ontleed, terwyl die taalkunde die linguistiese struktuur van 'n verskeidenheid tekste wil beskryf en die taalbeheersing of taalgebruikskunde wil die funksionele teks ontleed en daaroor advies gee ten einde die kommunikatiewe $k$ waliteit van die teks te verbeter. 
Maar uiteindelik is die teks vir al hierdie dissiplines die sentrale objek, en daarom word daar geargumenteer dat die verskil tussen die dissiplines ten minste op die eerste vlak in die graad van kreatiwiteit van die teks gesoek kan word. Die taal-, letterkunde, skryfkuns en die taalgebruikskunde sou dus saamgevat kon word onder die sambreelterm: tekswetenskappe.

\section{Bibliografie}

Broden, Thomas $F$. 1999. Linguistic semantics for literature and the human sciences today. Semiotica, $124(1 / 2): 81-127$.

Carstens, W.A.M. 1997. Afrikaanse tekslinguistiek. Pretoria : Van Schaik.

De Wet, Gerda. (red.) 1998. Taal en kommunikasie. S.A. Tydskrif vir Taalkunde, Supplement 35, Sept.

Drury, John. 1991. Creating poetry. Cincinnati : Writers' Digest Books.

Du Plessis, Hans. 1981. Nadruk: 'n Grammatiese manifestasie van 'n nie-grammatiese faktor. Taalfasette (nuwe reeks), 1(1): 13-16, Sept.

Du Plessis, Hans. 1983. Die verband tussen taal- en letterkunde. In: Sinclair, A.J.L. (red.) G.S. Nienaber - 'n huldeblyk. Kaapstad : Universiteit van Wes-Kaapland. p. 157-166.

Gräbe, I. 1979. Teoriee oor hoofaspekte van poëtiese taalgebruik. Potchefstroom $\mathrm{PU}$ vir $\mathrm{CHO}$. (Proefskrif.)

Jansen, Frank. 1998. In search of valid advice for the optimalization of functional texts: Introduction to communication studies in the Netherlands. S.A. Tydskrif vir Taalkunde, Supplement 35: 15-26

Johl, Ronel. 1991. Teks en konteks. In: Cloete, T.T. (red.) Literêre terme en teorieë. Pretoria : HAUM-literêr. p. 530-531.

Lyons, John. 1977. Semantics 2. London: Cambridge University Press.

Maes, A., Van Hauwermeiren, P. \& Van Wes, L. (reds.) 1994. Perspectieven in taalbeheersingsonderzoek. Dordrecht : ICG Publications.

Ross, J.R. 1973. Nouniness. In: Fujimurs, O. (red.) Three dimensions of linguistic theory. New York: TEC Co. p 79-91.

Scholtz, M. 1978. Die metafoor. In: Snyman, Henning (red.) Uit vier windstreke: Studies opgedra aan prof. Meyer de Villiers. Kaapstad : Tafelberg.

Snyman, Henning. 1981. Verkenningsv/ugte. Johannesburg: Perskor.

\section{Kernbegrippe:}

fokusarea: tale

kreatiwiteitsgraad

meerduidigheid

teksgrense

tekstipe

skryfkuns

\section{Key concepts:}

creative writing
degree of creativity
focus area: languages
text boundaries
text type
valencies of meaning

